\title{
ESTADO E POLÍTICAS PÚBLICAS PARA O LIVRO DIDÁTICO NO BRASIL
}

\author{
STATE AND PUBLIC POLICIES FOR THE DIDÁTICO BOOK IN BRAZIL
}

\author{
Fernando Garcez de MELO ${ }^{1}$
}

RESUMO: Este trabalho objetiva analisar as bases constitutivas do livro didático no Brasil. Para tanto, ultrapassa seus caracteres pedagógicos imediatos como seus conteúdos e ideologia intrínseco e busca captar os seus pressupostos políticos e econômicos. Com esta análise almejasse melhor compreender o livro didático que é distribuído pelo governo federal por meio do Programa Nacional do Livro Didático (PNLD) aos professores e alunos das escolas públicas, e é recurso privilegiado para realização da prática pedagógica.

PALAVRAS-CHAVE: Estado. Políticas educacionais. Livro didático.

ABSTRACT: This work aims to analyze the constitutive bases of the textbook in Brazil. Therefore, beyond its immediate pedagogical characters as its content and intrinsic ideology and seeks to capture its political and economic assumptions. This analysis craved better understand the textbook that is distributed by the federal government through the National Textbook Program (PNLD) to teachers and students from public schools, and is a privileged resource for realization of pedagogical practice.

KEYWORDS: State. Educational policies. Textbook.

\section{Introdução}

O livro didático como instrumento pedagógico possibilitador da aquisição de conhecimento apresenta um caráter dual, por um lado, de contribuir para a apreensão de saberes necessários ao desenvolvimento humano e sua intervenção na sociedade e, por outro lado, o simples treinamento repetitivo de capacidades cognitivas e um conformismo frente os problemas da sociedade. Essas funções se materializam conforme a complexa rede de relações entre o aluno, professor, autor, editor, sociedade,

${ }^{1}$ Mestre em Educação: Políticas Públicas e Gestão da Educação. Universidade do Estado de Mato Grosso. Email: garcez@unemat.br 
Estado, entre outros, que irão definir o que e como a prática pedagógica deve ser orientada, balizada por interesses de classe.

O professor da educação básica e o seu livro didático têm íntimas relações e, por vezes, intrincadas. No imaginário social é difícil vislumbrar um sem o outro por que é seu instrumento de trabalho. A relação do professor da educação básica com seu instrumento de trabalho apresenta-se de diferentes formas: a) com o professor utilizando-o para desenvolver o processo de ensino-aprendizagem; b) o instrumento se impondo ao professor, como que lhe ditando a forma de trabalho; c) o professor renegando a validade do instrumento lhe disponibilizado e construindo seus próprios instrumentos. Não obstante, também consideramos que essas formas se apresentam inter-relacionadas. Esta relação entre sujeito e objeto, que por vezes é invertida, não se explica unicamente pela atitude do professor. Este constrói sua prática pedagógica, mas em um contexto dado, limitado por condições objetivas como as políticas públicas. Disto, depreende-se o objetivo de analisar as bases constitutivas do livro didático no Brasil. Para tanto, ultrapassamos seus caracteres pedagógicos imediatos como seus conteúdos e ideologia intrínseco e buscamos captar os seus pressupostos políticos e econômicos, nos levando a uma digressão sobre Estado e políticas educacionais.

A justificativa para o presente estudo é o fato do Programa Nacional do Livro Didático (PNLD) e o Programa Nacional do Livro Didático para o Ensino Médio (PNLEM) disponibilizar aos professores de todo o Brasil o livro didático indicando o amplo alcance dessa política educacional. Em termos econômicos ${ }^{2}$, dados relativos à produção editorial brasileira vêm indicando que o impresso didático desempenha um papel extremamente importante no quadro mesmo dessa produção mais geral. Ou seja, os livros didáticos são um dos subsetores de livros mais vendidos no Brasil. Além disso, investigações têm mostrado que o livro didático e a escola estabelecem relações complexas com o mundo da cultura, isto é, os livros didáticos não consistiriam apenas numa adaptação simplificada, para fins escolares, de conteúdos produzidos no campo da cultura e da ciência (BATISTA, 2007, p.533).

O trabalho está estruturado em duas seções: na primeira, discutiremos o Estado a partir do pensamento de Karl Marx e Émile Durkheim que nos dará subsídios para analisarmos como as políticas públicas são delineadas na sociedade. Os trabalhos de

2 Para ilustrar no período de 1995-2004 o governo federal destinou recursos na ordem de R\$ 4.247.637.706, beneficiando 30.758.413 alunos e 163.715 escolas (Fonte: MEC/FNDE). <http://www.fnde.gov.br/home/index.jsp?arquivo=livro_didatico.html\#legislacao> 
Azevedo (2001) e Höfling (2001) também contribuem para compreender as políticas públicas gestadas pelo Estado. Na segunda seção, apresentaremos as bases históricas e políticas para constituição do livro didático no Brasil, refletindo sobre: i) a intervenção do Banco Mundial (SILVA, 2002; CORAGGIO, 2007) e, ii) a estratégia de aglutinação dos conteúdos a partir da lógica de desconcentração e regulação/regulamentação (CASSIANO, 2007; LIMA, 2004; BARROSO, 2005). Nas considerações finais resgatamos os principais aspectos discutidos apontando as problemáticas do modo de pensar e agir do Estado, favorecendo o baixo rendimento no processo ensinoaprendizagem e uma formação limitada no que tange o desenvolvimento humano responsável com a sociedade.

\section{O Estado e as políticas educacionais}

Compreender o Estado e as políticas educacionais por ele implementada nos leva a necessidade de relacioná-lo com a própria sociedade e o mercado. Contudo, ele próprio é compreendido de diferentes formas, o que resulta em diferentes tendências de como ele atua ou mesmo de como ele deve atuar a fim de garantir o desenvolvimento da sociedade. Uma análise profunda exige a compreensão da concepção de mundo, de homem e do próprio desenvolvimento histórico desse Estado e suas formas de governo. No entanto, nos limitaremos a traçar alguns aspectos para a compreensão de Estado a partir de dois pensadores, Karl Marx e Émile Durkheim, a fim de compreendermos as políticas educacionais empreendidas pelo Estado no presente momento histórico.

Sinteticamente, para nossa análise, destacaremos a relação entre o Estado e o mercado por entender que eles possibilitam uma compreensão ilustrativa sobre o modo de funcionamento da sociedade. Por um lado, temos o Estado entendido como "o conjunto de instituições permanentes - como órgãos legislativos, tribunais, exército e outras que não formam um bloco monolítico necessariamente - que possibilitam a ação do governo" (HÖFLING, 2001, p. 31) e, por outro, o mercado lugar onde se comerciam mercadorias e há interação entre compradores e vendedores. Estes são conceitos restritos e provisórios, apenas para situar em termos gerais e posteriormente o analisarmos no sentido axiológico. 
A partir desse contexto, depreenderemos nossa análise sobre os dois autores referidos. Em Durkheim (2002, p.71), temos o Estado como "um órgão especial encarregado de elaborar certas representações que valem para a coletividade. Essas representações distinguem-se das outras representações coletivas por seu maior grau de consciência e de reflexão". Essa compreensão é fruto de sua análise sobre as formas de relação do indivíduo consigo mesmo, com os grupos familiares passando pelas relações de grupos profissionais e tendo os chamados grupos políticos como os mais extensos. Neste último é característico a distinção entre governantes e governados, base para a consolidação da sociedade política.

O desenvolvimento da sociedade indica que os indivíduos desenvolvem-se de forma diferenciada, sendo assim os governantes serão aqueles com maior grau de consciência e de reflexão, enquanto que os governados se submetem as regras morais e jurídicas. Daí o Estado ser um grupo de funcionários sui generis que elaboram as representações para a coletividade. Está concepção demonstra o Estado como uma instituição superior aos indivíduos. O Estado não pode se submeter imediatamente aos anseios da população que não tem mais do que um pensamento sincrético e caótico. $O$ primado da sociedade sobre o indivíduo tem ao menos dois sentidos, segundo Aron (1993, p.301): $i$ ) as sociedades coletivistas, onde cada um se assemelha a todos, vêm historicamente em primeiro lugar, e ii) a solidariedade mecânica ${ }^{3}$ precede a solidariedade orgânica ${ }^{4}$.

Estes primados demonstram o desenvolvimento da sociedade e dos indivíduos, que inicialmente os homens se relacionavam diretamente (solidariedade mecânica) e a divisão do trabalho propiciou o desenvolvimento da solidariedade orgânica em que instâncias mais altas medeiam às relações entre os indivíduos. Esta instância é o próprio Estado, soberano para governar e garantir a própria vida do indivíduo. Temos então que, ao mesmo tempo em que Estado e indivíduo se diferenciam, eles se aproximam, pois o indivíduo supera seu modo de vida restrito à natureza e se eleva moralmente por meio da sociedade e do Estado. "Quanto mais forte for o Estado, tanto mais o indivíduo é respeitado" (DURKHEIM, 2002, p.81). O indivíduo fora da sociedade, despido de tudo quanto for de origem social, é análogo a um animal. O grupo social que lhe dá força

\footnotetext{
${ }^{3}$ Solidariedade mecânica é uma solidariedade por semelhança. Os indivíduos se assemelham porque experimentam os mesmos sentimentos, aderem aos mesmos valores.

${ }^{4} \mathrm{Na}$ solidariedade orgânica, em decorrência da divisão do trabalho, os indivíduos por vezes não se relacionam diretamente, isto é, cada um desempenha sua própria função e diferente dos demais tendo ciência que todos são indispensáveis à vida.
} 
moral e é entendido como maior do que a soma das partes, portanto legitimo de subordinar as partes que não vivem sem sua dependência. Cabe então ao Estado propiciar a sociedade harmônica em que libere o desenvolvimento dos indivíduos. Porém "não é um determinado indivíduo que o Estado procura desenvolver, é o indivíduo in genere, que não se confunde com nenhum de nós" (DURKHEIM, 2002, p.64). Podemos dizer que é um indivíduo abstrato, não coincide com nenhum de nós.

Para evitar a total submissão do indivíduo ao Estado assume papel mister os grupos intermediários (grupos profissionais). Estes atuam como intermediários na relação Estado e sociedade por representarem os interesses mais gerais de um grupo específico e assim não deixar o Estado a mercê de interesses imediatistas da população.

Karl Marx não desenvolve uma teoria do Estado, contudo suas análises acerca do modo de produção da sociedade dão elementos para pensarmos o Estado de forma histórica e não abstratamente. Desta forma, segundo Marx e Engels (2007, p.10):

\begin{abstract}
As premissas de que partimos não são bases arbitrárias, dogmas; são bases reais que só podemos abstrair na imaginação. São os indivíduos reais, sua ação e as suas condições materiais de existência, tanto as que eles já encontraram prontas, como aquelas engendradas de sua própria ação. Estas bases são pois verificáveis por vias puramente empírica.
\end{abstract}

Essa premissa norteia, por exemplo, sua análise empreendida acerca da obra de Hegel - Princípios da filosofia do direito - afirmando que este entende o Estado como sujeito, e que o predicado é a sociedade civil (MARX, 2005). Isto é, Hegel entende que o Estado é que gera a sociedade civil, enquanto Marx defende que a sociedade civil gera o Estado.

Ao entender que o indivíduo desenvolve-se a partir das suas condições materiais de existência temos que este apropriasse constantemente de novos saberes e instrumentos de trabalho. Assim o homem produz seus meios de subsistência e os aperfeiçoa em quantidade e qualidade. O curso de desenvolvimento histórico do homem torna-se um constante embate com natureza, mas também com outros homens para sua sobrevivência. Porquanto, o Estado é criado a partir da necessidade dos homens, os quais foram se organizando e criando estruturas de poder. Por sua vez, essas estruturas serviram hegemonicamente para os grupos dominantes. Para Marx e Engels (2007, p.74), "o Estado adquiriu uma existência particular ao lado da sociedade civil e fora dela, mas este Estado não é senão a forma de organização dos burgueses”. 
Considerando que vivemos sob o modo de produção capitalista caracterizado pela primazia do mercado como locus privilegiado de desenvolvimento da sociedade e que as revoluções industriais e tecnológicas, bem como o desenvolvimento das relações de mercado, propiciaram a ascensão da classe burguesa ao poder, tanto econômico quanto político. A ascensão desta à classe dominante contribui na universalização de seus valores e representações como de todas as demais classes e grupos, tais como: o individualismo e a competitividade. Em certa medida ocorre a universalidade desses princípios, contudo devemos considerar que eles não são absolutos e que a classe proletária manifestasse constantemente contra eles.

Levando em conta que o pensamento marxista é aberto e permite múltiplas leituras, consideraremos, conforme Offe (apud Höfling, 2001, p.33), que "o Estado atua como regulador das relações sociais a serviço da manutenção das relações capitalista em seu conjunto, e não especificamente a serviço dos interesses do capital - a despeito de reconhecer a dominação deste nas relações de classe". Isto significa fundamentalmente que o Estado baliza, por meio de doutrinas e diretrizes, a organização da sociedade fazendo com que a balança penda para a concorrência e não para um desenvolvimento racional da humanidade. Na lógica capitalista a concorrência funciona como elemento estimulante despertando nos indivíduos e empresas a necessidade de se aprimorarem. Assim no mercado aqueles mais desenvolvidos e preparados irão se sobrepor e de forma justa.

Este processo competitivo também ocorre na educação, entendendo esta como uma política pública social, de responsabilidade do Estado - mas não pensada somente por seus organismos. Sendo de responsabilidade do Estado cabe identificar as bases do pensamento que a norteia. Azevedo (2001) ao investigar diferentes formas de pensamento político na educação realiza uma discussão sobre a abordagem neoliberal, a teoria liberal moderna da cidadania, o paradigma marxista e a interseção entre elas. Destacamos que a teoria liberal moderna tem suas raízes no pensamento de Durkheim, diferentemente da abordagem neoliberal que acentua a função do mercado, nessa o bem-estar e a igualdade constituem-se em pré-requisitos indispensáveis ao exercício pleno da individualidade e da liberdade. Isto significa legitimar o aprofundamento da ação estatal na economia e reconhecer que as políticas educacionais constroem-se a partir das lutas históricas dos trabalhadores por emprego e direitos ao trabalho. 
Segundo Azevedo (2001, p.22-23) as contribuições de Durkheim se refere a constatação da crescente especialização e diferenciação das funções trabalhistas e que estavam ruindo os valores comuns. A solidariedade mecânica, em alguma medida, dava lugar à solidariedade orgânica que engendrava novas regras morais e estava baseada na cooperação da interdependência de novas funções. Como essa cooperação não ocorria espontaneamente, era função do Estado estabelecer uma regulamentação para que ela se efetivasse. Era necessário aumentar o poder regulatório sem suprimir a liberdade individual, cria-se assim uma nova acepção sobre a igualdade de chance que é a chamada igualdade de condições exteriores. Nesta não basta o respeito à liberdade de cada um competir por emprego e educação de acordo com seu talento inato. Para Azevedo (2001, p.23) esse pensamento “supõe pré-requisitos básicos e essenciais, referenciados ao mundo do trabalho, como os cuidados com a preparação, qualificação, manutenção e reprodução da própria força de trabalho". Contudo, devemos frisar que essa análise da política social, que tem em Durkheim uma referência, dever ser entendida como instrumento importante no sentido de amenizar as desigualdades originadas no mercado. Portanto, é um pensamento de justiça nos marcos da sociedade capitalista. E a educação para esse Estado tem a função de inculcar nos indivíduos normas, valores e atitudes que possibilitem a formação de agentes sociais e políticos.

$\mathrm{Na}$ sociedade capitalista, regida por um pensamento (neo)liberal, o Estado e o mercado têm relações, ou mesmo interseções, que iremos, brevemente, situar para compreender a conjuntura das políticas educacionais. Para garantir os direitos individuais - direito à vida, à liberdade, à propriedade privada - o indivíduo deve ter liberdade para buscar, pelos seus próprios modos, uma forma de viver. Nas palavras de Adam Smith (apud Höfling, 2001, p.36):

Deixe-se a cada qual, enquanto não violar as leis da justiça, perfeita liberdade de ir em busca de seu próprio interesse, a seu próprio modo, e faça com que tanto seu trabalho como seu capital concorram com os de qualquer outra pessoa ou categoria de pessoas.

Desse pensamento que desdobra-se na expressão "menos Estado e mais mercado", isto é, que o Estado deve atuar apenas como regulador das relações sociais a serviço da manutenção das relações capitalista e o mercado é o espaço privilegiado onde as relações sociais (troca, compra e venda de mercadorias, fundamentalmente) ocorrem e propiciam o desenvolvimento social. Não desconsideramos que no mercado também há 
as trocas simbólicas que envolvem a cultura, contudo, o destaque para os aspectos mercadológicos foi intencional para demonstrar que, na perspectiva (neo)liberal, são estes que constituem o seu cerne. E sob essa lógica mercadológica, e princípios como da relação custo-benefício, que as políticas educacionais podem ser elaboradas e implementadas.

\section{Das políticas dos livros didáticos aos professores}

A constituição do livro didático nos remete a um arcabouço legislativo, bem como ao contexto sócio-político em que foi desenvolvido. Este arcabouço exerce uma função de regulação, termo polissêmico e que nos exige maior precisão. Barroso (2005) apresenta diferentes conceitos e contexto em que este é utilizado, para nosso intento, basta acentuar que a entenderemos como "um processo constitutivo de qualquer sistema e tem por principal função assegurar o equilíbrio, a coerência, mas também a transformação desse mesmo sistema" (BARROSO, 2005, p.733). Além disso, podemos identificar que em um dado fenômeno encontramos multi-reguladores, isto é, um processo em que várias instituições interferem na regulação.

$\mathrm{Na}$ sala de aula, professores e alunos leem e realizam as atividades propostas nesses manuais. O que não significa, imediatamente, que adotem as ideologias intrínsecas. Desde o decreto-lei n. 1006/1938 que ao professor é dado o direito de escolher o livro a ser adotado, mesmo que limitado por uma lista de obras aprovadas por uma comissão do governo. Devemos considerar que naquele momento histórico, década de 1940, temos uma significativa discussão em defesa da escola pública, gratuita, laica e obrigatória; desdobramento do Manifesto dos Pioneiros da Escola Nova (1932) tendo Anísio Teixeira e Fernando Azevedo como expoentes dessa defesa. A necessidade de instruir e educar o povo eram entendidos como uma tarefa premente se se pretende um desenvolvimento econômico no Brasil.

A construção de escolas, formação de professores, fornecimento de merenda escolar, ensino para todos eram desafios a serem superados. Em respeito à infância, fase da vida entendida como peculiar e que deve ser respeitada pelos educadores e adultos, o ensino deve propiciar prazer e ter uma funcionalidade. Permitir o desabrochar desse novo ser é possibilitar ao seu ritmo interno, biológico, desenvolver todas suas 
faculdades. Para tanto, a reorganização dos conteúdos para sua assimilação pelos alunos propicia a construção de livros voltados exclusivamente para essa fase da vida e para o ambiente escolar. Didaticamente, esta pode ser uma justificativa para o desenvolvimento dos livros didáticos naquele período. Desta forma, materializasse o pensamento de Comênio (1592-1670) que em sua Didáctica Magna propugna meios para garantir o ensino para todos.

Não obstante, devemos considerar que a produção do livro didático para as políticas educacionais é menos oneroso se comparado, por exemplo, a remuneração do professor, e também de mais fácil controle do processo de ensino-aprendizagem. Isso poderia impedir a difusão de conteúdos ideológicos diferente da classe dominante.

As bases do livro didático, isto é, as políticas educacionais e sua configuração nas salas de aula foram gestadas em meio a embates no processo histórico. Cabe assinalar que ele está vinculado a um ideal de qualidade de educação que, por sua vez, assenta-se em um pensamento político e econômico mais amplo.

Uma forma de identificar o ideal de educação é analisar os planos nacionais de educação que, também, apresenta-se como um elemento regulador. Segundo Fonseca $(2009$, p.155) "Os planos, portanto, fixam valores e diretrizes que devem ser conhecidos e debatidos em todas as instâncias responsáveis pela ação educativa e, obrigatoriamente, com a participação direta dos profissionais da escola". Identificar seus valores e diretrizes, por sua vez, implica uma análise mais ampla acerca da conjuntura política e econômica. A justificativa é que mesmo entendendo a elaboração de políticas públicas para a educação como fruto de um embate entre diferentes grupos e classes sociais interpretamos que na formulação das políticas educacionais, ao longo da história, os fatores intervenientes do campo econômico se sobrepõe aos educacionais.

A explicação sobre os princípios econômicos balizarem as políticas educacionais exige maiores esclarecimentos, o que passamos a fazer nesse momento. Retomando o pensamento de Fonseca (2009, p.172), em seu estudo é demonstrado que "os planos [da educação] incorporaram, com mais ou menos intensidade, o substrato econômico que sustentou os diferentes projetos nacionais de desenvolvimento". Sendo que os educadores faziam um contrapeso ao proporem projetos emancipatórios que, em certa medida, foram contemplados. Mas a autora explica que na prática predominou a lógica econômica que prioriza as atividades instrumentais e a administração de meios, bem como o favorecimento da criação do espírito de competitividade expresso nas inúmeras 
avaliações externas para medir o grau de eficiência e eficácia do ensino. É possível perceber a materialidade desse pensamento por meio de conceitos mais operativos como: custo-benefício, custo-qualidade e determinantes da educabilidade.

Podemos identificar problemas diversos que levaram às reformas do Estado numa perspectiva neoliberal: o fim da ditadura militar e a comprovação de que o "milagre econômico" obtido nesse período foi fruto do grande endividamento das finanças públicas; os Estados de bem-estar social da Europa estavam em barrocada, não devendo serem mais tomados como exemplo para o desenvolvimento da nação; a crise do socialismo real e uma falaciosa vitória do capitalismo como modo de produção justo e eficaz para o desenvolvimento social; etc. Não será discutido aqui as problemáticas em torno dos problemas citados. Para o objetivo desse trabalho cabe assinalar que esses problemas deram força a uma acentuação das ações liberais em todo mundo. Marcando, profundamente, importantes conquistas sociais, tais como: a previdência, o trabalho, a saúde e a educação.

Corroborou para esse processo os organismos financeiros internacionais que por meio de uma série de estratégias conseguiram adentrar e intervir nas políticas de diversos países. Abordaremos como desencadeou esse processo no Brasil por meio do Banco Mundial. Esta instituição, bem como o Fundo Monetário Internacional (FMI), foram criadas em 1944, e, segundo Silva (2005), “juntas tornaram-se as guardiãs dos interesses do capital e com capacidade para induzir políticas econômicas e o destino de continentes e países em todo o planeta". Como nos mostra Coraggio (2007), a contribuição mais importante do Banco Mundial é seu trabalho de assessoria, concebido para ajudar os governos a desenvolver políticas educativas adequadas às especificidades de seus países. São fundamentalmente ideias sob o mote de "assistência técnica" que influenciam nossas políticas, e conseguem adentrar em nosso país por conta de empréstimos permeados de condicionalidades, isto é, dotadas de condições prédeterminadas.

As ideias proferidas por essas instituições implicam em reformas neoliberais. Segundo Moraes (2002, p.15): “O neoliberalismo econômico acentua a supremacia do mercado como mecanismo de alocação de recursos, distribuição de bens, serviços e rendas, remunerador dos empenhos e engenhos inclusive. Nesse imaginário, o mercado é matriz da riqueza, da eficiência e da justiça." Tal imaginário pode ser identificado nos próprios documentos do Banco em que defendem a reforma do Estado para diminuir os 
gastos com assistência social; diminuir os gastos públicos com funcionários, objetivando aumentar a agilidade e a eficácia; no caso da educação, priorizar o investimento em insumos materiais, formação em serviço, ensino técnico e investimento na educação básica em detrimento do ensino superior.

O êxito em materializar esse pensamento é mediado pelos conflitos entre agentes externos e os internos. A intervenção é concretizada ao fim de um processo intrincado em que o governo federal e estadual, bem como as elites nacionais consentem e legitimam a implantação dessas reformas. Esse consentimento pode ser verificado por ausência de limites das atribuições do governo federal sobrepondo-se às leis constitucionais; na centralização dos processos decisórios; na banalização das desigualdades regionais e sociais; na permeabilidade aos interesses dos credores externos; no enfraquecimento das instituições nacionais, especialmente, as educacionais (SILVA, 1999). Ocorre que na América Latina vários países receberam assistência e empréstimos do Banco Mundial e, mesmo guardando semelhança nos aspectos estruturais, conforme a negociação em cada país que era definido onde seriam alocados os recursos. Para exemplificar, mesmo o Banco em sua cartilha não incentivando o gasto no ensino superior, na Argentina foi financiado projeto nesse âmbito (CORAGGIO, 2007).

Dentro desse arcabouço de prioridades estabelecidas pelo Banco Mundial e aceitas pelos governos e elites nacionais ganha pertinência as políticas para o livro didático. O Programa Nacional do Livro Didático ${ }^{5}$ (PNLD), criado em 1985, instituí a distribuição de livros escolares aos estudantes matriculados nas escolas públicas de $1^{\circ}$ Grau. Passa por mudanças significativas em 1996 como o estabelecimento da avaliação das obras didáticas que seriam distribuídas aos professores de todo o país. O Fundo Nacional para o Desenvolvimento da Educação (FNDE), autarquia responsável pela execução do Programa Nacional do Livro Didático (PNLD), é responsável pela compra e distribuição dos livros didáticos de todo o Brasil, dentre outras atribuições, tais como: triagem e avaliação das obras, elaboração do guia do livro didático. Neste início de século XXI temos significativa expansão das políticas de livros didáticos. Além da distribuição de livros didáticos para o ensino fundamental, também são distribuídos: no ensino médio, na Educação de Jovens e Adultos, bem como a distribuição de dicionários de língua portuguesa e obras em braille. E, a partir de 2004, com a

${ }^{5}$ Decreto n. ${ }^{\circ} 91.542$ de 19 de agosto de 1985. 
Resolução $n^{\circ} 40$, de 24/8/2004, ficou instituído o atendimento aos alunos da educação especial das redes pública e privada definidas pelo censo escolar. $\mathrm{Na}$ rede privada, somente recebem livros os estudantes portadores de necessidades educacionais especiais das escolas filantrópicas e comunitárias.

O estabelecimento da avaliação das obras didáticas, em 1996, e em especial na primeira avaliação, gerou grande rebuliço, inclusive ganhando a imprensa sensacionalista, devido à constatação de inúmeros problemas das obras: preconceitos contra negros, índios e mulheres, erros conceituais, metodologias de ensino ultrapassadas. Isto resultou em protestos por parte da Associação Brasileira de Livros (ABRALE) que passou a cobrar maior transparência do processo avaliativo. Também autores considerados de renome no circuito nacional recorreram aos jornais para criticarem o governo e se diferenciarem dos ditos autores ruins. Os professores foram silenciados nesse processo.

Para além dessa polêmica, identificou-se como o governo criou formas de estabelecer a reforma curricular aos seus moldes e sem democracia. Uma estratégia utilizada foi à criação dos Parâmetros Curriculares Nacionais (PCNs). Segundo Paulo Renato de Souza (Souza, 2005, p. 123), então Ministro da Educação do governo Fernando Henrique Cardoso,

\begin{abstract}
Ao final, prevaleceu a orientação de elaborar um parâmetro curricular nacional ou um referencial curricular nacional para evitar justamente os entraves legais; um parâmetro ou referencial não é obrigatório nem fere a autonomia de Estados e Municípios. De todo o modo, se o parâmetro ou o referencial são de boa qualidade, acabam se impondo. Essa tendência no Brasil foi reforçada e acelerada pelo fato de o Ministério ser um grande comprador de livros didáticos e ter introduzido, a partir de 1996, a avaliação desses livros com base precisamente nesses parâmetros.
\end{abstract}

Está posto assim como o governo federal realizou a aglutinação do conteúdo escolar (CASSIANO, 2007). Este processo nos indica a forma como o Estado pensa e age nas políticas educacionais. Ele atua centralizando as principais decisões e descentraliza (ou desresponsabiliza-se) de funções secundárias. Segundo Lima (2004) essas políticas ocorrem no sentido de desconcentração que é redistribuir responsabilidades e manter o poder de definições centralizado. Soma-se a isso a constante desvalorização da carreira docente que dificulta a escolha de melhores quadros de profissionais para exercer a função docente, a falta de infra-estrutura, 
sobrecarga de trabalho, são fatores que podem contribuir para que o livro didático tornese recurso central utilizado nas salas de aula.

Tornando-se recurso central, em que medida o livro didático possibilitará enriquecer o processo de ensino e aprendizagem? A avaliação estabelecida em 1996 contribuiu para a diminuição dos erros conceituais e do preconceito contra negros, índios, mulheres e deficientes, mas ainda há aspectos para serem superados, por exemplo, no que tange a história da África (OLIVA, 2003). Quanto ao caráter ideológico dessas obras, ainda é tema para grande discussão. Temos autoras como Dias e Abreu (2006, p.304) entendendo que "no caso dos livros didáticos, ocorre a apropriação dos conceitos dos discursos sociais e econômicos que valorizam o conhecimento científico-tecnológico submetido à lógica do mercado", ou, ainda nessa perspectiva, para Santanna e Bettini (s/d), "há todo um mecanismo bem estruturado que atinge diversas dimensões sociais com sua ideologia [neoliberal], ou seja, expande à todos o seu modo de compreender a sociedade, e ao mesmo tempo, camufla as contradições e explorações que o homem sofre". Enquanto que autor como Dinis Filho (2009) discute que os livros didáticos de Geografia, sob o mote de serem críticos realizam uma doutrinação teórica e ideológica de esquerda, com destaque para o pensamento marxista. Estes estudos mostram que houve avanços e que alguns problemas persistem, e em relação ao seu conteúdo há controvérsias.

Por fim, devemos reconhecer a limitação intrínseca do próprio recurso didático. “A compreensão do que é dito não se esgota na racionalidade do texto. Faz parte dessa compreensão um certo grau de persuasão, e sua eficácia depende da correspondência que tenha com o mapa cognitivo do receptor" (FERREIRA, 1995, p. 104). Como temos uma seleção nacional dos livros didáticos, estes por sua vez, são elaborados tendo por base um aluno abstrato, sem reconhecer as suas condições de aprendizagem. É o professor na sala de aula que esperasse tenha condição de realizar a correspondência entre o conteúdo a ser ensinado com o mapa cognitivo do receptor.

\section{Considerações finais}

A forte influência do Banco Mundial na política pública educacional, por meio de suas condicionalidades e o consentimento do governo e elites nacionais corroborou o 
viés economicista na formulação destas políticas. A partir dessa lógica de raciocínio destacamos que houve um privilegiamento de investimento em recursos materiais que ocorreu por meio da expansão das políticas de livros didáticos, em detrimento do investimento em recursos humanos. Ou seja, a carreira docente é desestimulante tendo em vista a sua remuneração e condições de trabalho.

A principal estratégia adota e implementada para priorizar o livro didático, ocorreu durante o governo de Fernando Henrique Cardoso, com a elaboração dos PCNs e a avaliação dos livros didáticos com base precisamente nestes. Isto contribui para a aglutinação dos conteúdos escolares segundo diretrizes de um seleto grupo de profissionais. Identificamos nesse processo um Estado Durkheiminiano que, por ter uma compreensão mais elaborada sobre a realidade, deve balizar as ações dos indivíduos. Ou seja, nessa ótica, os professores são postos como executores de propostas elaboradas por especialistas.

A implicação na prática pedagógica seria a prevalência do objeto (livro didático) sobre o sujeito (professor). Essa inversão subsume o professor na relação pedagógica. As limitações desse fato decorrem do livro didático ter um caráter genérico, dificultando a aproximação do conteúdo com a realidade do aluno, bem como a possibilidade de estabelecer propostas inadequadas de ensino. Trata-se, portanto, de efetivamente por o professor como sujeito construtor da prática pedagógica.

No entanto, para que isso ocorra, não podemos restringirmo-nos aos aspectos pedagógicos ou a simples atitude do professor. A contradição a ser superada é justamente os pressupostos econômicos e políticos que interferem nesse processo.

Num esforço de síntese, podemos concluir que as bases constitutivas do livro didático no Brasil são: i) de viés economicista, isto é, privilegia aspectos econômicos como a relação custo-benefício e não aspectos pedagógicos visando o melhor aproveitando de alunos e professores; ii) de política liberal, que concentra os poderes decisórios na instância mais alta e redistribui responsabilidades sob a lógica da competitividade e da produtividade.

\section{Referências}


ARON, R. As etapas do pensamento sociológico. 4. ed. São Paulo: Martins Fontes, 1993.

AZEVEDO, J. M. L. A educação como política pública. 2. ed. Campinas, SP: Autores Associados, 2001.

BARROSO, J. O Estado, a educação e a regulação das políticas públicas. Educação e Sociedade. Campinas/SP: CEDES, vol. 26, n. 92, Especial, out/2005.

BATISTA, Antônio A. G. Um objeto variável e instável: textos, impressos e livros didáticos. In: ABREU, Márcia (org.) Leitura, história e história da leitura. 2 Reimp. Campinas: SP. Mercado de Letras: Associação de Leitura do Brasil; São Paulo: FAPESP, 2007.

CASSIANO, C. C. F. O mercado de livros didáticos no Brasil: da criação do Programa Nacional do Livro Didático (PNLD) à entrada do capital internacional espanhol (1985-2007). 2007. 252 f. Tese (Doutorado em Educação: História, Política e Sociedade), Faculdade de Educação, Pontifícia Universidade Católica de São Paulo, São Paulo, 2007.

CORAGGIO, J. L. Propostas do Banco Mundial para a educação: sentido oculto ou problemas de concepção? In: TOMASI, L.; WARDE, M. J.; HADDAD, S. (org.). O Banco Mundial e as políticas educacionais. São Paulo: Cortez, 2003.

DIAS, R. E. e ABREU, R. G. Discursos do mundo do trabalho nos livros didáticos do ensino médio. Revista Brasileira de Educação, v. 11, n. 32, 2006.

DINIS FILHO, L. L. A situação do ensino no Brasil: doutrinação ideológica e incapacidade de desenvolver competências. Disponível em: <http://www.escolasempartido.org/index.php?id=> Acesso em: 20 de maio de 2010.

DURKHEIM, É. Lições de sociologia: a moral, o direito e o estado. São Paulo: EDUSP, 2002.

FERREIRA, N. T. Cidadania: uma questão para a educação. 2. ed. Rio de Janeiro: Nova Fronteira, 1995.

FONSECA, M. Políticas públicas para a qualidade da educação brasileira: entre o utilitarismo econômico e a responsabilidade social. Cadernos Cedes. vol.29 n.78 Campinas. 2009

HÖFLING, E. M. Estado e Políticas (Públicas) sociais. Cadernos Cedes, ano XXI, n. $55,2001$.

LIMA, A. B. Estado, políticas públicas e educação no Brasil. In: LIMA, A. B (org.). Estado, políticas educacionais e gestão compartilhada. São Paulo: Xamã, 2004.

MARX, K e ENGELS, F. A ideologia alemã. 3. ed. São Paulo: Martins Fontes, 2007.

MARX, K. O 18 Brumário de Louis Bonaparte. São Paulo: Moraes, 1987.

MARX, K. Crítica da filosofia do direito de Hegel. São Paulo: Boitempo, 2005. 
MORAES, R. C. Reformas neoliberais e políticas públicas: hegemonia ideológica e redefinição das relações Estado-sociedade. Educação e Sociedade. vol. 23, n.80, 2002.

OLIVA, A. R. A História da África nos bancos escolares. Representações e imprecisões na literatura didática. Estudos Afro-Asiáticos, Ano 25, n. 3, 2003.

SANTANNA, A.; BETTINI, R. F. A. J. Ideologia no livro didático de história: um diálogo inicial. Texto não publicado $(\mathrm{s} / \mathrm{d})$.

SILVA, M. A. Políticas para a educação pública: a intervenção das instituições financeiras internacionais e o consentimento nacional. 1999. $327 \mathrm{f}$. Tese (Doutorado em Educação). Faculdade de Educação, Universidade Estadual de Campinas, Campinas, 1999.

SILVA, M. A. O consenso de Washington e a privatização na educação brasileira. Linhas críticas, Brasília, v. 11, n. 21, jul./dez. 2005.

SOUZA, P. R. A revolução gerenciada: educação no Brasil (1995 - 2002). São Paulo: Prentice Hall, 2005.

\section{Como referenciar este artigo}

MELO; Fernando Garcez de. Estado e políticas públicas para o livro didático no Brasil. Revista on line de Política e Gestão Educacional, Araraquara, v.20, n.03, p. 547-562, 2016. Disponível em: <http://dx.doi.org/10.22633/rpge.v20.n3.9716>. ISSN: 15199029.

Submetido em: junho/2016

Aprovado em: setembro/2016 